\title{
Seven Epochēs
}

Lester Embree, Dept of Philosophy, Florida Atlantic University, Boca Raton, FL

Email:embree@fau.edu

\section{ABSTRACT}

Some clarification is attempted for concepts of what is often loosely called "phenomenological reduction” in general and its most important species for the cultural disciplines.

\section{INTRODUCTION}

In a philosopher of Husserlian background, some uses of the expression "phenomenological reduction," especially by colleagues in other cultural sciences, often motivate puzzlement and pondering. In order not to embarrass others needlessly, the present effort will not document curious occurrences of this expression. Instead, it will try to clarify seven concepts of specific procedures and, first of all, their genus and then to offer specific expressions for them the use of which might reduce confusion and obscurity. This is not an exercise in scholarship. Rather, some freedom has been taken to simplify and also to extend and describe some constitutivephenomenological methodology. Whether the following account is true in whole or part must be judged by the reader through further reflective observation and analysis of his or her practice of research.

\section{Some Generic Terms}

"Reduction" is a short form for what at least oral tradition reports was fully expressed by Edmund Husserl with the phrase that translates as "epoche, reduction, and purification." Strictly speaking, "epoche" names a mental operation, "reduction" refers to a consequent change in the researcher's attitude, and "purification" refers to a consequent change in the thing-as-intended-to whereby something is somehow purified in some respect and thereby becomes in some respect pure. Because it is what effects such changes, "epoche” is a better short form to name the whole than "reduction." But even Husserl tended to use "reduction" as the short form, which I shall not.

The Greek word "epoche" seems best translated as "suspension” or, better, "suspending of acceptance." This invites the telling of what is suspended and/or is suspended from, i.e., the starting place, and also of what the suspending is performed to gain. And it is best to specify an 
epoche by what is to be gained by it, e.g., the "transcendental epoche"” is performed to gain mind in its non-worldly or transcendental status. What the suspending proceeds from in this case is mind as it is first found, which is to say in the spatio-temporal world. The "natural" or, better, "worldly attitude" begun from is, moreover, simultaneously reduced by the transcendental epoche to the "transcendental attitude."

In all cases, the attitudes that epochès produce reduction from are the attitudes that are automatically returned to when the specific epoche is relaxed. Thus, without the mentioned transcendental epoche, the mind is in the worldly attitude and is accepting of itself as in the spatio-temporal world. At least in titles for the various procedures, the word "epoche" alone is useful because it is more concise than the full-fledged expression "epoche, reduction, and purification." These generic concepts may become clearer as various species of epoche are described in what follows.

\section{The Theoretical Epochē}

If one adopts the theoretical attitude, one suspends acceptance of things as practical, which is to say as ends and means, and/or one suspends acceptance of things as "aesthetic" in a maximally broad signification, i.e., as objects of enjoyment or suffering. Thereby, one gains a theoretically pure object. The thing may continue to have its usefulness or attractiveness for others, but for the researcher such are suspended. ("Thing" is used here in the broad signification whereby anything and everything is a thing.) The theoretical attitude is sometimes referred to as "detachment." Phenomenological investigation always proceeds in a theoretical attitude. It may be a matter of course for well-prepared philosophers and scientists that one adopt and proceed in a specific theoretical attitude, but it is ultimately more responsible to recognize explicitly how an attitude is taken up through a specific epoche and how there is a correlative purification of the object. This can also foster better research.

The use of the expression "pure" in the signification of "theoretically pure" is older than the phenomenological tradition, for there has long been "pure logic" and "pure mathematics." In these cases, purity appears to be gained through suspension of what is essential to logic when it is practical in so-called "practical logic" or when mathematics is practical in so-called "applied mathematics.”

Incidentally, while theoretical epoche valuably does show at least the place for foundations in theoretical science of a practical disciple, e.g., the pure psychology underlying psychotherapy, the adjective "applied" in "applied science" can connote that there were scientific foundations established prior to the existence of the practical discipline, but this is often not the case. There has been skillful nursing for millennia before such scientific foundations began being sought in nursing research. "Science-based practical discipline" might be a better expression, especially if it leads to inquiry into the bases or foundations. And it is an interesting question whether "aesthetic" in a broad signification or predominantly valuational disciplines have or can have scientific foundations sought and found for them as well, perhaps in advertising or in nutrition. 


\section{Eidetic Epochē}

Particulars or individuals, serious or fictive, always already have universal essences or eidē cointended with them. Such co-intended universals are originally vague and relate only to what has already actually been perceived or feigned and can thus be called "empirical types," as Husserl does in Erfahrung und Urteil.

The "eidetic epoche" consists in suspending acceptance of the particular in order to gain the purely essential. Husserl's free phantasy variation then helps in the further clarification of such universals, which are grasped in eidetic evidencing. Eidetic epoche is alternative to the empirical or, better, factual just as theoretical epoche is alternative to the practical and the "aesthetic." Eidetic results are ultimately sought in phenomenology and most if not all cognitive disciplines, but empirical or factual cases can also be pursued as illustrative examples of what is asserted eidetically and also in the historical parts of various disciplines that have them.

\section{No Reflective Epochē}

Because there is a change of attitude when one goes over from straightforward living to reflective observation, analysis, and description in phenomenological investigation, one might think that there is an epoche behind that change. Actually, however, reflection is only a shift in attention so that the appearances, manners of givenness, and thetic qualities of the things intended to and the components of the mental processes intentive to them that had been "overlooked," so to speak, are focused on. Analogously, recollection is also a shift in attention from perception or from expectation. There is no reflective epoche.

Incidentally, however, it deserves mention that reflection can take not only the form of "selfobservation," but also that of what can be called "reflection on Others." Straightforwardly, one might perceive an Other watching a child play with a dog and a ball and then recognize the Other's amusement at the spectacle and even how she follows with her eyes how the happy child is able to catch and throw the ball and even the eagerness of the dog fetching it. There is thus some access to the mental lives of others. It is also an interesting question whether there is not only such individual but also collective self-reflection and even reflection on groups of Others. Thus in the latter respect, is it possible in sports for one team collectively to assess the morale of the opposite team.

\section{The Naturalistic Epochē}

Originally, things concretely have positive and negative intrinsic and extrinsic, firm and shaky, etc., values and uses as well as doxic or belief characteristics. These characteristics are constituted in collective and individual life and are thus cultural. These are products of learning in the broad signification. By what is best called the naturalistic epoche these cultural characteristics can be suspended and purely naturalistic objects gained. The diamond that is a 
girl's best friend can become in the geology laboratory purely a sample of crystalline carbon and a pet can become a zoological specimen.

There certainly are naturalist foundations for cultural characteristics, e.g., something must be hard, heavy, and rather unbreakable to found usefulness of a means for the purpose of hammering, so an apple or a light bulb will not work. However, the search for naturalistic foundations, which also helps responding to the threat of cultural relativism, is no excuse for forgetting that things are originally cultural. This is among the reasons why the present writer prefers to speak of the "cultural sciences" rather than the "human sciences." Another reason is that humans are not the only species with culture and something can be learned from comparisons with cultural lives of Others with little or no language. Some tribes of chimpanzees crack nuts with stones that are then hammers.

In this age of naturalism, however, how objects are originally cultural is underappreciated, and this is even the case in the phenomenological tradition. One might think that naturalism, which is at root the view that all things are concretely rather than abstractly natural and perhaps that culture can be explained as a matter solely of language, is a habitual and traditional naturalistic epoche. This is not the occasion to pursue the issue, but it might still be suggested that naturalism is a superadded cultural pattern of interpretation rather than a manner in which things are originally encountered.

\section{The Physicalistic Epochē}

It is arguable that all things are originally encountered as alive. ${ }^{i}$ In that case, there is need for an epoche to gain the purely inanimate or physical. This is probably not recognized in most theory of the physical sciences, but history and cultural anthropology show that there is a great deal of animism in human life. Or if one recognizes that human and non-human animals are alive, one can wonder how they can be considered merely physical and chemical systems.

The physicalistic epoche is the suspending of acceptance of animateness, i.e., mind in the things encountered, and then there is a physicalistic attitude and physically pure objects in astronomy, chemistry, geology, physics, etc. Some philosopher/scientists once thought that astronomical bodies are alive (Bruno was burned at the stake for accepting the sun as God's body, was he not?) Behaviorism has physicalism this in psychology more recently.

\section{The Egological Epochēe}

The complex attitude that we begin in is not only worldly, factual, and cultural, but also intersubjective. This signifies at first that there is more than one mind who is actual or possible within the world and that things are correlatively objective or, better, "public" for us and that we are originally co-subjects in collectivities or groups of various sorts. That we are often only temporarily members of these or those groups ought not to obscure our essential membership. 
By the "egological epoche" this can be changed such that all things other than oneself, Others included, are objects for a self and are "private" also in one signification of the word. And then there are egologically pure objects and also an egological attitude from which one returns to the intersubjective attitude when the egological epoche is relaxed. An intersubjective attitude is also essential for science because any objectivity of scientific findings is constituted in collectivities of relevant scientific specialists.

There are two general approaches in the cultural sciences depending on whether egological epoche is relied on or not. Methodological individualism is one and methodological collectivism is the other. One often hears it said these days that phenomenology proceeds in the first person perspective, but it might be suggested that one then ask whether the first person singular or the first person plural is intended. And just as there is an interpretive tendency toward naturalism in some cultures, there can also be an interpretive tendency toward individualism or egoism that can be understood and similarly dealt with as well.

\section{The Solipsistic Epochē}

To gain a view of the origins of how Others are ultimately constituted in selves, one can perform what seems best called the "solipsistic epochē." Here one's research field is temporarily purified of all Others, so that one is utterly but temporarily alone and can better appreciate the pairing of one's own mind with one's body and, for that matter, with one's products or artifacts. When this epoche is relaxed, one returns at least to the egological but usually beyond that to the intersubjective attitude and public world.

\section{The Historical Epochēe?}

Because the historical and social-scientific disciplines are different, one can wonder if there is an epoche by which the distinctive attitude of one or the other is established. Since we seem originally to be focused on the contemporary world, it would seem that an epoche is needed to gain an attitude in which, among other things, present life is recognized as the effect of earlier times in collective life. And from here one can go on to wonder about epochēs distinctive of other disciplines such as linguistics and psychiatry.

\section{Psychological Epochē}

Modern educated people believe in sound waves, photons, brain states, etc., impacting on our sense organs and helping to cause what is sensuously perceived. This is another form of interpretation in some cultures. If one suspends acceptance of such external and not directly observable factors, "phenomenological psychological epoche" can be spoken of and the purely sensuous in objects observed and reflected on. 


\section{Transcendental Epochē}

According to Husserl, we are originally in the "natural attitude," which to avoid naturalism is better called the "worldly attitude." By this attitude, minds are, as mentioned, accepted as in the spatio-temporal world, apparently through identifications of the inner time of mental life with the temporal dimension of the space-time in which grass grows and of the motivational patterns in mental life with causal relations among natural objects. The worldliness of minds can be suspended through transcendental epoche $\bar{e}$ and then minds are gained in a non-worldly or transcendental status. This is important if one seeks in the way of modern philosophy to ground the world and the positive sciences of aspects of it in transcendental intersubjectivity without recourse to a ground that is still part of the world, which is as absurd as literally pulling oneself up by one's own boot stops.

\section{Closing Remarks}

Epochēs are rarely performed alone. Since the Ideen of 1913, Husserl's first philosophy is explicitly both eidetically and transcendentally pure, but it is also implicitly theoretically, egologically, and often seems naturalistically pure as well. The practical benefit for research of methodologically recognizing the actually eight epochess described here is the help in being sure about the approach one wants to be taking.

It is good in cultural disciplines practical as well as theoretical to have some sense of what the transcendental epoche, reduction, and purification consists in and why it is resorted to. It would be relevant for a transcendental philosophy of nursing but not for the methodology or theory of nursing that usually suffices for nursing. Similarly, the physicalistic and especially solipsistic epochēs seem of little use in the cultural disciplines beyond philosophy. Because of the novelty of their descriptions, the eidetic and transcendental epochess have received the most attention historically.

But the transcendental epoche is unnecessary beyond philosophy and, while the new account in Husserl is helpful to recognize, eidetic epochē seems always already resorted to unconsciously by competent intellectuals. Recognition of the theoretical and psychological epochēs, however, might be most helpful, the former in prompting reflection on foundations in science-based disciplines and the latter in resisting imperialistic tendencies today that are currently spreading from cognitive science.

Finally, the association of two of the most famous epochess, the psychological and the transcendental, with the disciplines of psychology and philosophy suggests that there might be other epochēs specific to other disciplines. Perhaps there is an economic epoche in which considerations of the social system in contrast with the economic system are suspended, an epoche for sociology and child psychology in which middle-class expectations in the investigator are suspended for the sake of better grasping the outlook of the member of another class or age, an epoche in cultural anthropology in which the outlook of one's own culture is suspended in order to investigate that of the others thematized, etc. But these are issues for further investigations. 
${ }^{i}$ Lester, Embree, "Aufbau to Animism: A Sketch of the Alternate Methodology and Major Discovery in Dorion Cairns's Revision of Edmund Husserl's 'Fifth Cartesian Meditation,'” The Continental Philosophy Review. 39/2 (2006). 